ISSN 1982-8713

\title{
Religión y Desarrollo: el Budismo desde India Hacia Sri Lanka: la Donación (Dana) y sus Potencialidades Comunitarias para el Desarrollo209
}

\author{
Religião e Desenvolvimento: o Budismo da Índia até Sri Lanka: a Doação \\ (Dana) e suas Potencialidades Comunitárias para o Desenvolvimento.
}

\begin{abstract}
Lía Rodriguez de la Vega ${ }^{1}$
${ }^{1}$ CICS-UP and Master Program in Social Sciences, Faculty of Social Sciences. Universidad Nacional de Lomas de Zamora - UNLZ. Universidad de Palermo - UP. Universidad Nacional del Chaco Austral - UNCAus. Asociación Latinoamericana de Estudios de Asia y Africa - ALADAA. Comité de Asuntos Asiáticos del Consejo Argentino para las Relaciones Internacionales - CARI. E-mail: liadelavega@hotmail.com.
\end{abstract}

Recebido em 29 de Julho de 2020; Aceito em 28 de outubro de 2020.

DOI: $10.12957 /$ nearco.2020.54878

\section{Resumen}

El budismo surgió en India hacia el siglo VI AC y aunque ya hacia el siglo XII el número de sus practicantes se había reducido en el país, la creencia se proyectaría hacia el resto de Asia y el mundo. Es el caso de Sri Lanka adonde el budismo llegó en el siglo III AC, de acuerdo al texto del Dīpavaṃsa (la más antigua crónica histórica del país) y con él, llegó el núcleo valórico y la cultura material que le son propios. Así, el budismo Theravada, practicado en la isla, tiene como meta última, el nibbana/nirvana, que se consigue a través de la práctica de la meditación (bhavana), acciones correctas (sila) y el logro de las diez perfecciones (dasa paramita), entre las cuales se encuentra la donación (dana). Una de las formas en que la donación (dana) puede ser practicada es, precisamente, la donación de partes corporales. En ese marco, en 1961, se estableció en Sri Lanka la Sociedad de Donación de Ojos de Sri Lanka (Sri Lankan Eye Donation Society), desarrollada por los trabajos del Dr. Hudson Silva, cuyos servicios alcanzan diversos países, haciendo de Sri Lanka uno de los mayores exportadores de córneas. Atendiendo a lo mencionado, en el contexto de la relación entre espiritualidad/religión y desarrollo, este texto reflexiona sobre las características budistas, que potenciaron el desarrollo de esta iniciativa de alcance colectivo, revisando someramente la normativa relacionada al tema, en el marco del desarrollo humano.

Palabras clave: Sri Lanka; India; Budismo.

${ }^{209}$ El texto no cuenta con los signos diacríticos de los términos en sánscrito y pali. 
ISSN 1982-8713

\section{Resumo}

O budismo surgiu na Índia por volta do século VII aC e, embora no século XI o número de seus praticantes tenha reduzido no país, a crença se espalhou para o resto da Ásia e do mundo. É o caso do Sri Lanka, onde o budismo teria chegado no século $11 \mathrm{aC}$, segundo o texto da Dīpavaṃsa (a mais antiga crônica histórica do país) e com ela chegou o núcleo de valores e a cultura material que lhe são próprios. Assim, o Budismo Theravada, praticado na ilha, tem como objetivo final o nibbana/nirvana que é alcançado através da prática da meditação (bhavana), ações corretas (sila) e a obtenção das dez perfeições (dasa paramita), entre que é a doação (dana). Uma das maneiras pelas quais a doação (dana) pode ser praticada é justamente através da doação de partes do corpo. Nesse contexto, em 1961, foi criada no Sri Lanka a Sociedade de Doação de Olhos do Sri Lanka, desenvolvida a partir dos trabalhos do Dr. Hudson Silva, cujos serviços alcançam diversos países, tornando o Sri Lanka um dos maiores exportadores de córneas. Considerando o exposto, no contexto da relação entre espiritualidade/religião e desenvolvimento, este texto reflete sobre as características budistas, que promoveram o desenvolvimento desta iniciativa de âmbito coletivo, fazendo uma breve revisão das regulamentações relacionadas ao tema, no âmbito do desenvolvimento humano.

Palavras-chave: Sri Lanka; India; Budismo.

\section{Introducción}

La relación entre espiritualidad/religión y desarrollo ha sido dejada de lado durante largo tiempo, recibiendo una mayor atención más recientemente (GOULET, 1980; ALKIRE, 2002; DENEULIN; REKODI, 2011). Este cambio en la consideración de la relación entre religión y desarrollo se da en un contexto de modificación del rol de la religión en la arena internacional, caracterizada por una presencia más visible en diversos ámbitos, una mayor atención a la importancia de las matrices culturales en las dinámicas sociales en general y en el desarrollo en particular, una mayor difusión de otras perspectivas acerca de lo que una buen vida es y el modo como eso se traduce en cada comunidad en particular, un consecuente mayor protagonismo de actores sociales relacionados a espacios religiosos sobre distintos temas.

Entre los abordajes académicos que el tema ha ido concitando puede mencionarse a Ver Beek (2000), que alude a la espiritualidad como un taboo dentro del 
ámbito del desarrollo y revisa la entonces pobre presencia de la temática en tres journals reconocidos dedicados al desarrollo; Candland (2000), que alude a la noción de la fe como una forma de capital social, que contribuye a la construcción de redes entre las personas, tomando en cuenta los señalamientos de Drèze y Sen (1995) acerca de que la expansión de oportunidades sociales no pueden ser garantizada solamente por agencias gubernamentales o mecanismo del mercado sino que deben ser alcanzados por la acción pública -aunque apunta que los autores no comentan las condiciones de tal acción-, analizando el uso de ese capital social en los casos que considera. Thodock (2005), por su parte, aborda la cuestión de los actores no gubernamentales (NGOs), relacionados a la religión, en su caso el Movimiento Sarvodaya (Sri Lanka), que a su entender "ofrece un modelo alternativo para un desarrollo sostenible e inclusivo que también tenga un atractivo moral universal", señalando la autora el surgimiento de modelos alternativos a los paradigmas de desarrollo occidental, en Asia del Sur, mientras Deneulin y Rakodi (2011), repasan la cuestión, recorriendo las diversas producciones sobre el tema, revisando el cambio de lugar de la religión en la dinámica mundial, etc.

Por otro lado, las creencias y prácticas religiosas han sido señaladas por académicos que abordan el enfoque de Desarrollo Humano y Capabilidades como aspectos de la movilización social, que demandan consideración y resultan relevantes para el desarrollo-sin dejar de tener presente que esas creencias, en algunas circunstancias pueden también incitar a la violencia, obstruir el empoderamiento, etc.(ALKIRE, 2002, 2004; WHITE y DENEULIN, 2009; BROWN, DENEULIN and DEVINE, 2009).

Considerando lo señalado y la actualidad del tema, este texto aborda el caso de la Sri Lankan Eye Donation Society, establecida en 1961, a resultas del trabajo del Dr. Hudson Silva, cuyos servicios alcanzan diversos países. Esta tarea se relaciona con el Budismo Theravada, cuya meta última, el nibbana, se consigue a través de la práctica de la meditación (bhavana), acciones correctas (sila) y el logro de las diez perfecciones (dasa paramita), entre las cuales se encuentra la donación (dana), una de cuyas formas es la 
ISSN 1982-8713

donación de partes corporales. A cuento de ello, en el contexto de la relación entre espiritualidad/religión y desarrollo, el trabajo reflexiona sobre las características budistas, que potenciaron el desarrollo de esta iniciativa, revisando someramente la normativa relativa a la temática en el país, en el marco del desarrollo humano.

\section{Nociones de abordaje: cultura e identidad}

Giménez (2005) señala que el entender y definir la cultura por referencia a los procesos simbólicos de la sociedad, hace posible asignarle a la misma un campo específico y autónomo como una dimensión de la vida de la sociedad.

Ello a su vez, apunta a que la cultura se particulariza y pluraliza en lo que Sewell (1999) denomina "mundos culturales concretos" (p. 52), de tal manera que podemos hablar de "las culturas". A su vez, la consideración de la cultura interiorizada conlleva hablar de las identidades sociales.

Por su parte, Grimson (2012), establece una distinción entre cultura e identidad, apuntando que entiende que lo cultural alude a las prácticas, creencias y significados rutinarios y sedimentados, al tiempo que lo identitario refiere a los sentimientos de pertenencia a un colectivo.

Finalmente, Restrepo (2010) señala que las identidades son relacionales, es decir que se producen a través de la diferencia y aluden tanto a I diferencia como a la desigualdad y la dominación.

\section{El desarrollo}


ISSN 1982-8713

Valcárcel (2006) señala que el concepto de desarrollo fue antecedido por otros como progreso, civilización, crecimiento, riqueza, evolución, etc. En 1942, un funcionario de la Organización Internacional del Trabajo mencionó en un informe el término "áreas subdesarrolladas", aunque el término "subdesarrollo" no alcanzó mayor notoriedad sino hasta 1949 , en que fue utilizado por el presidente norteamericano Harry Truman, en el discurso inaugural de su mandato.

El término ha adquirido el alcance de la época en que se consideraba, siendo asociado a aumento o mejora de algo, ligado a los bienes materiales y posteriormente asociado también a virtudes/bondades no solamente materiales.

A partir de la década del '70 (del siglo XX), cobró notoriedad en su abordaje, la consideración del medioambiente. Hacia la década del '80, la propuesta de Manfred Max Neef hablaría del desarrollo a escala humana, revalorando la diversidad y considerando necesidades y satisfactores. En línea con ese planteo, llegaría también el de Amartya Sen y su consideración de que el referente del desarrollo no es el crecimiento económico sino los seres humanos. Por su parte, abrevando en distintos abordajes, en la década del '90 habría de llegar la propuesta de Naciones Unidas, que sería la del desarrollo humano, definido como:

\footnotetext{
un proceso mediante el cual se amplían las oportunidades de los individuos, las más importantes de las cuales son una vida prolongada y saludable, el acceso a la educación y el disfrute de un nivel de vida decente. Otras oportunidades incluyen la libertad política, la garantía de los derechos humanos y el respeto a sí mismo... (PNUD, 1990, p.33).
}

Con el paso del tiempo se sumarían otros elementos a tal definición.

Posteriormente, la denominada corriente del post-desarrollo habría de criticar el concepto, concibiéndolo como un discurso del poder, que presenta a las personas una imagen negativa de sí mismas, en términos de retardo o inadaptación en relación a la 
situación de los pueblos más industrializados. Por ello, dicha corriente rechaza la definición universal de desarrollo y asocia el concepto a los valores de una cultura específica (la occidental).

En la visión del desarrollo, el cuerpo ocupa un lugar destacado, relativo a la salud biológica y social.

\section{El cuerpo como vector de significación}

El cuerpo constituye, al decir de Le Breton (2002) el vector semántico a través del que se construye la evidencia de la relación del actor social con el mundo y es desde él desde donde surgen, al tiempo que se propagan distintas significaciones que forman la base de la existencia, tanto individual como colectiva. El cuerpo resulta así el eje de la relación con el mundo, el tiempo y el lugar en que la existencia se hace carne por medio de la mirada del actor, la materialización, de su situación biográfica. Es a través de su condición corpórea que el sujeto transforma el mundo en un tejido cercano y coherente, disponible tanto para su accionar como para su comprensión y entendimiento. Tanto emitiendo como recibiendo, el cuerpo produce sentido de manera permanente y es así que el sujeto se inserta de modo activo en un espacio social y cultural dado. El orden social se filtra a través del cuerpo.

Asociado a lo señalado, las representaciones del cuerpo son función de las representaciones de las personas y ambas se encuentran insertas en la visión que del mundo tiene la comunidad de pertenencia. De esta manera, la concepción moderna del cuerpo, considera al sujeto separado del cosmos, de los otros y de sí, sin embargo, existen sociedades donde tal separación no existe y el cuerpo está inscripto en una red compleja de correspondencias-entre ese cuerpo y el cosmos-, modificándose la relación entre el cuerpo y sus representaciones de una sociedad a otra. En las sociedades, existen de ese modo, varios modelos de cuerpo, asociados a distintas medicinas (el saber biomédico formal y dominante, las medicinas paralelas o populares, etc.). 
El autor agrega que el cuerpo está en el cruce de las distintas instancias de la cultura, en la base de todas las prácticas sociales, como mediador de la presencia humana, siendo el espacio de imputación del campo simbólico. Por eso, resulta fundamental tener presente que el cuerpo no existe en su forma natural sino que está siempre inserto en una trama de sentido, metaforizando lo social y siendo metaforizado a su vez por ello.

\section{El budismo y su propuesta}

Surgido en la India (siglo VI AC), el Budismo, es generalmente caracterizado como una religión, en función de poseer diversos elementos que permiten tal asociación, como: un sistema de creencias, una organización institucional en torno de creencias y prácticas rituales, un discurso ético basado en diversas enseñanzas y creencias, especialistas religiosos en su sistema monástico, etc., aunque su no creencia en un principio que sobreviva a la vida física de un individuo y tampoco en un principio Supremo -cuyo lugar está ocupado aquí por el Vacío (en cuanto se sostiene que la verdadera naturaleza de las cosas es la inexistencia de ser propio) (VON GLASENAPP, 1991-1992), lo diferencia de otras creencias.

En su marco, el ser humano es un conjunto de dharmas (dhammas, en pali ${ }^{210}$ ) insustanciales e impermanentes, afirmándose la existencia de una sucesión de reencarnaciones (samsara), con la paradoja de un ciclo de transmigraciones sin que haya algo/alguien que transmigre (atendiendo a la doctrina de no existencia de un sí mismo/anattam). Postula también el anaditva (inexistencia de comienzo), la creencia en el karman (que alude a la retribución de los actos) (DE LA VALLÉE POUSSIN, 1994; DRAGONETTI; TOLA, 2004), sosteniendo que es posible romper la cadena de

\footnotetext{
${ }^{210}$ Los dharmas son los elementos constitutivos de las entidades que componen nuestra realidad (TOLA y DRAGONETTI, 2004).
} 
reencarnaciones recurriendo a doctrinas y prácticas salvíficas que él propone, alcanzando la liberación o nirvana (en sánscrito/nibbana, en pali) (DE JONG, 1994-1995). Enuncia la doctrina de las Cuatro Nobles Verdades (que señala que los objetos del apego son dolorosos, que el origen del dolor es el deseo, que la supresión del dolor es la extinción del deseo y que el camino para la supresión del dolor está dado por el Noble Óctuple Camino, camino virtuoso por él propuesto). Otro de sus planteos fundamentales se expresa en la Pratityasamutpada o teoría del Surgimiento Condicionado, cadena causal de doce miembros que explican el nacimiento y la cesación del dolor, inspirada en dos características intelectuales del Budismo, la visión causalista de la realidad y la concepción de la interdependencia universal de todo (DRAGONETTI; TOLA, 2004).

Su destacada propuesta ética (ahimsa/no violencia); karuna/compasión; paciencia/ksanti, etc.) (DRAGONETTI; TOLA, 2004), se extiende a todos los seres sintientes y al mundo. Resulta central a él, lo comunitario y en ese marco, sobre la base de la interdependencia universal, se agrega la centralidad del dar, como una acción kármicamente fructífera, a su vez ligada al compartir los frutos kármicos de la acción.

Kaman (2016) señala que la ética budista está hecha del Dhamma (la doctrina, que aborda los principios) y del Vinaya, (la disciplina, es decir las normas y circunstancias de aplicación práctica de tales principios). De esta manera, la ética de la acción humana (karma), resulta especialmente relevante en el budismo, en tanto a través de ella puede regularse la causalidad moral, el mundo de acción, la escatología y la soteriología. En ese marco, la primera virtud ética considerada es dana, que constituye la base para el desarrollo tanto moral como espiritual, siendo el centro de tal generosidad, la comunidad o sangha. Recordemos que el Dhammapada 223, alude a "conquistar al tacaño a través del dar". Por otro lado, la caridad aparece mencionada entre los diez buenos caminos de acción (dasa- kusalakarmapatha). 
NEARCD: Revista Eletrônica de Antiguidade 2020, Volume XII, Número II - ISSN IS82-8713

Núcleo de Estudas da Antiguidade - NEA

Universidade do Estado do Rio de Janeiro

ISSN 1982-8713

Con respecto a la corporalidad, paralelo a la idea del ser humano como un conjunto de dharmas tanto insustanciales como impermanentes, es conocido que la preservación y circulación de las denominadas "reliquias" resulta de gran relevancia en el budismo y ellas aluden tanto a restos corporales como a objetos utilizados por un "santo" budista. En ambos casos, la importancia de la consagración material de tales reliquias, da cuenta de la cultura material associada. Las circunstancias que rodean las reliquias alcanzan incluso proyección internacional, como sucedió, a modo de ejemplo, con las reliquias de dos de los discípulos más cercanos de Buda, Sariputta y Moggallana, que habían sido descubiertas por Maisey y Cunningham en una estupa en Sanchi, en 1851 y habían sido llevadas al Reino Unido. La Sociedad Maha Bodhi, apoyada por el gobierno indio reclamaron tales reliquias, que fueron re-consagradas en el mismo lugar en noviembre de 1952, estando cinco años en circulación entre Ceylán e India (donde fueron recibidas por el entonces Primer Ministro Jawaharlal Nehru) (BREKKE, 2007). Otros ejemplos más cercanos en el tiempo pueden darse con la circulación de una urna con cenizas de Buda desde Sri Lanka a Nagpur, India (lugar donde Bhimrao Ambedkar se convirtiese al budismo, seguido por cientos de miles de dalits, en 1956), en ocasión de una Conferencia Internacional Budista, en 2015, con el apoyo y promoción del gobierno indio. Otro ejemplo posterior, se dio durante la visita del Primer Ministro indio, Narendra Modi, en 2017, a Sri Lanka, en ocasión de participar del Día Internacional de Vesak, ocasión en la que rezó en el Templo de la Reliquia Sagrada del Diente (de Buda) ${ }^{211}$, en Kandy (Hindustan Times, 2017).

Como señala Harvey, 2011, citado en MacCormick, 2013:

\footnotetext{
${ }^{211}$ Cabe recordar que tras la muerte de Buda, en el siglo VI AC, sus cenizas fueron distribuidas en ocho partes para distintos reinos $v$ se conservaron en ocho estupas diferentes, en el norte de la India. De acuerdo a los textos budistas, en el siglo III AC, el conocido emperador Ashoka, de la dinastía Maurya, sacó las reliquias de estupas y las redistribuyó en todo el subcontinente, lo que contribuyó a la difusión del budismo (algunos estudiosos asumen esto como un hecho y otros lo ponen en duda). Su hijo Mahendra, llevó una reliquia de Buda a Sri Lanka (un diente), que se conserva en el templo mencionado (BREKKE, 2007).
} 
La perspectiva [budista] ve la moralidad como parte de un camino espiritual que en gran parte consiste en cultivar un carácter más saludable, socavando las impurezas morales/ espirituales y cultivando la virtudes de contraataque... Esto implica que lo que uno hace, y cómo y por qué lo hace es de gran importancia: para las acciones de uno, ambos expresan y dan forma al propio carácter y contribuyen al propio destino.

Así, en el budismo Theravada, el acceso a y la realización del nirvana, se logra por medio de bhavana (meditación/cultivo de la mente-tomando en cuenta que la conciencia que resulta de los hitos espirituales en el camino budista, se denomina phala/fruto), sila (disciplina moral) y la realización de dasa paramita (diez perfecciones) ${ }^{212}$-de entre las cuales, la primera es dana/generosidad ${ }^{213}$, donación(RATNAYAKA, 1985; WIJAYANTO, 2009). A su vez, los actos relativos al dar, son juzgados tomando en cuenta la calidad del motivo del donante -es decir su intención ${ }^{214}$-, la pureza espiritual del recipiente y la clase y tamaño de lo dado. La acción de dar debe ser desinteresada, recibida con humildad y guardar proporción con la necesidad que busca atender. Tales actos poseen diversas consecuencias: crean mérito en el próximo mundo para los dadores y pasan los beneficios al individuo destinatario, cuya satisfacción constituirá la base de una sociedad mejor.

\footnotetext{
212 Ellas son: Dana (generosidad/donación), Sila (conducta apropiada/disciplina moral) Nekkhamma (renuncia), Paññā (conocimiento), Viriya (energía), Khanti (paciencia), Sacca (honestidad), Adhițțhana (determinación), Metta (benevolencia), Upekkha (ecuanimidad).

${ }^{213}$ Sudyka (2013) y Heim (2004/2015, de manera más extensa) exploran dana en un contexto más amplio que considera la India, a través del budismo, el hinduismo y el jainismo e incluso Copeman (2011) explora la translocalidad de dana.

${ }^{214}$ La intención/volición (cetana) especifica si un momento de conciencia es saludable, insano o neutral. En el contexto de la intención correcta, el Canon Pali describe tres tipos: a) intención de renuncia, b) intención de buena voluntad y c) intención de inocuidad, que a su vez actúan como antídotos contra los tres tipos de intenciones equivocadas, caracterizadas por ansia / codicia (lobha), mala voluntad (dosa) e ilusión moha (DE SILVA, 2006). De acuerdo a la filosofía budista, una acción es considerada buena o mala atendiendo principalmente a la intención que subyace a ella y de acuerdo a eso, producirá frutos kármicos con resultados buenos o malos y creará también el hábito de hacer más acciones buenas o malas.
} 
NEARCD: Revista Eletrônica de Antiguidade 2020, Volume XII, Número II - ISSN IS82-8713

Núcleo de Estudas da Antiguidade - NEA

Universidade do Estado do Rio de Janeiro

ISSN 1982-8713

Existen en ese contexto tres formas de la práctica de dāna: a) el acto de donar los bienes mundanos -comida, trabajo, etc. (dana paramita), b) la donación de partes (anga) del cuerpo a los necesitados (dana upa paramita)-se habla aquí de "regalos del cuerpo" o dehadana- ${ }^{215}$ y c) el sacrificio de la vida por el bien de los demás (dana paramattha paramita) (RATNAYAKA, 1985). Tales actos son ilustrados en las denominadas vidas anteriores de Buda, en un cuerpo de textos dedicados a esas narraciones, conocidos como Jatakas (TOLA; DRAGONETTI, 2003), entre los que algunos de los más conocidos son el Sivi Jataka ${ }^{216}$ y el Vessantara Jataka ${ }^{217}$.

El Anguttara Nikaya ${ }^{218}$, 7, 6, Dhana Sutta: Treasure, señala que existen 7 tesoros, entre ellos, el tesoro de la generosidad. Y agrega: "Y cuál es el tesoro de la generosidad? Existe el caso de un discípulo de los nobles, su conciencia limpia de la mancha de avaricia, viviendo en casa, libremente generoso, con las manos abiertas, deleitándose en ser magnánimo, receptivo a los pedidos, deleitándose en la distribución de limosnas. Esto se llama el tesoro de la generosidad" (ȚHANISSARO BHIKKHU, 1997, párr. 7). Por su parte el Anguttara Nikaya, 8,54, el Dighajaṇu Sutta, destaca la generosidad como parte de una amistad virtuosa (kalyana-mittata) y como uno de los cuatros rasgos que llevan a la felicidad en las vidas futuras.

\footnotetext{
${ }^{215}$ Resulta relevante aquí atender a la noción de muerte, como es entendida por el budismo, atendiendo a que algunas donaciones de partes corporales sólo se hacen tras la muerte del donante. Así, los criterios budistas tradicionales se encuentran en en el Majjhima Nikāya y en ek Sampyutta Nikayas. Allí se alude a tres criterios que permiten distinguir un cuerpo vivo de uno muerto, a saber: vitalidad (ayu), calor (usma) y conciencia (viññana). Para más información sobre el tema puede consultarse Keown (2010).

${ }^{216}$ La historia narra una vida anterior de Buda, como el Rey Sivi, que residió en el norte de la ciudad india de Anuradhapura, hace varios miles de años, que decidió dar sus ojos a un brahmán ciego.

${ }^{217}$ Narra la historia que concluye la serie de relatos sobre las vidas anteriores de Buda y alude a su vida como el príncipe del reino Sivirat, Vessantara, que renuncia a sus posesiones e incluso sus hijos y esposa, lo que lo llevará a renacer como un Buda (LADWIG, 2009).

${ }^{218}$ Una de las colecciones del Sutta Pitaka, una de las tres cestas del Pali Pitaka (escrituras budistas) del budismo Theravada.
} 
NEARCD: Revista Eletrônica de Antiguidade 2020, Volume XII, Número II - ISSN IS82-8713

Núcleo de Estudas da Antiguidade - NEA

Universidade do Estado do Rio de Janeiro

ISSN 1982-8713

\section{El banco de ojos de sri lanka}

Gain, Jullienne, Zhiguo He, Aldossary, Acquart, Cognasse y Thuret (2016) señalan que el trasplante de córnea es el tipo de transplante más frecuente en todo el mundo, posibilitando la restauración de la función visual cuando el deterioro causado por daño corneal resulta demasiado severo para proporcionar una calidad de vida aceptable. Sumado a ello, la córnea presenta diversas características que hacen su almacenamiento y trasplante más fácil que otros tejidos y órganos. En ese marco, Sri Lanka se encuentra entre los mayores exportadores de córneas del mundo (Estados Unidos y Sri Lanka tienen las mayores tasa de donación de córneas per cápita del mundo, representando juntos el 94\% de las córneas exportadas en el mundo) (LAMBERT; CHAMBERLAIN, 2017).

Una de las manifestaciones concretas de estas ideas puede verse a través del trabajo de la Sociedad de Donación de Ojos de Sri Lanka ${ }^{219}$, cuyo desarrollo suele atribuirse a la tarea del Dr. Hudson Silva, quien, como estudiante de medicina en los años 50, reconoció la necesidad de donadores de córneas en el Colombo Eye Hospital. En función de ello y habiéndose agotado el suministro de córneas provenientes de presos-atendiendo a la abolición de la pena de muerte, en 1956, Silva inició una campaña para estimular la donación, logrando que muchos voluntarios se sumaran a esa acción. Cuando la Sociedad creó el Banco Internacional de Ojos, en 1961, el Dr. Silva se convirtió en su primer donante registrado y su madre en la segunda (siendo sus córneas transplantadas tras su muerte -en 1963-a un granjero quien, gracias a ello, recuperó la visión) (WIJERATNE, 2016). El servicio fue fortaleciéndose ${ }^{220}$ y pronto el

\footnotetext{
${ }^{219}$ Cabe señalar que Asia posee la mayor proporción de ceguera de córnea (2.8 millones de personas, sobre 10 millones del mundo).

${ }^{220}$ Contó con ayudas cruciales, como el apoyo público del Dr. A. Ariyaratne, líder de la respetada organización social budista de Sri Lanka, Sarvodaya (fundada oficialmente en 1958 para estimular la participación de jóvenes estudiantes en proyectos de desarrollo comunitario, a partir de una ideología de la educación y el desarrollo) (KLOPPENBORG, 1984); la firma del consentimiento de la Primer Ministro Sirimavo Bandaranaike, en 1972, para donar sus órganos, cosa que sería cumplida de modo público, etc. (SIMPSON, 2004).
} 
NEARCD: Revista Eletrônica de Antiguidade 2020, Volume XII, Número II - ISSN IS82-8713

Núcleo de Estudas da Antiguidade - NEA

Universidade do Estado do Rio de Janeiro

ISSN 1982-8713

suministro superó los límites de la demanda local, habiéndose transportado miles de córneas, a más de 60 países diferentes ${ }^{221}$ (SILVA, 1991). La práctica de exportar es refrendada con numerosas cartas de agradecimiento, elogios de autoridades, donaciones de diversos tipos, sin cuya asistencia, los servicios oftálmicos prestados por la sociedad no podrían funcionar.

En ese marco, para sortear la cuestión de la obtención del consentimiento de los familiares, se propuso el uso de un certificado impreso en el que se consiente expresamente la donación ${ }^{222}$, recomendándose que el mismo sea enmarcado y colocado en un lugar prominente de la casa. Los formularios de solicitud de donación, que deben ser refrendados por dos testigos, son impresos en tamil, sinhala e inglés (SIMPSON, 2017).

En Sri Lanka, la Ley de Trasplante de Tejidos humanos (THT) n· 48, de 1987 y las circulares del Director General de Salud (DGH) del Ministerio de Salud sobre el trasplante de órganos son los que establecen procedimientos para la donación y extracción de órganos y tejidos de cuerpos humanos, con diversos fines (terapéuticos, científicos, etc.). De acuerdo a la citada ley, cualquier persona mayor de 21 años puede consentir la donación por escrito, para que la misma entre en vigencia ante su fallecimiento, se trate de su cuerpo o cualquier parte o tejido del mismo, mientras ese consentimiento no se hubiese revocado. En aquellos casos en que el fallecido no haya dado su consentimiento en vida, será legal que consientan sus familiares, si el fallecido no se hubiese opuesto a

\footnotetext{
${ }^{221}$ Las primeras seis córneas que fueron donadas a un centro de salud extranjero, fueron llevadas por el Dr. Silva a Singapur, en 1964, en el Día de Vesak (WIJERATNE, 2016). En los primeros años de la década del '70, se iniciaron los primeros transplantes de córnea en Malasia, en el marco de una activa participación del Templo Maha Vihara y del templo budista de Sri Lanka en Kuala Lumpur, continuando hasta la actualidad la cooperación entre ambos países en este tema, con la colaboración de Sri Lankan Airways. También allí el dia de Vesak, se constituyó en un dia particular en el templo Maha Vihara para la recepción de córneas desde Sri Lanka (SCHREIBER, 2017). Otras historias similares dan cuenta de la práctica de dana con otras derivaciones como la donación de sangre (CHIEW, 2012).

${ }^{222}$ Ese certificado lleva impresa la frase: "vida a un ojo muerto" ("mala netata pana”).
} 
NEARCD: Revista Eletrônica de Antiguidade 2020, Volume XII, Número II - ISSN IS82-8713

Núcleo de Estudas da Antiguidade - NEA

Universidade do Estado do Rio de Janeiro

ISSN 1982-8713

la donación durante su vida (PERERA, 2009; VADYSINGHE; DASSANAYAKA; EDUSSUIRYA; RUKSHANA, 2018).

En el caso de las córneas, el consentimiento dado se hace de acuerdo a la Ley de Injerto de Córnea n· 38 de 1955 -primera legislación sobre la temática, que regula la donación post mortem de ojos, para propósitos terapéuticos-y la ya mencionada Ley de Transplantes de Tejido Humano n. 48 (Transplantation of Human Tissues Act, 1987; PERERA, 2009). La posición jurídica relativa a las transacciones de tejido humano en Sri Lanka está inspirada en los códigos internacionales de ética sobre trasplante de órganos y tejidos y resulta inaceptable comprar o vender el cuerpo o sus componentes. Al mismo tiempo, el cuerpo jurídico relacionado al tema resuena con la idea del mérito, que se mencionara. En ese contexto, los intentos de localizar las transacciones en el ámbito del parentesco y las obligaciones morales que existen entre parientes, constituye un espacio importante en contra de la comercialización de las partes donadas (SIMPSON, 2004).

Diversos agentes sociales como organizaciones comunitarias, corporaciones estatales y empresas desarrollan actividades promocionales relativas a la Sociedad. Los budistas constituyen la mayor base de apoyo para la donación de ojos y los monjes budistas han resultado fundamentales en su apoyo ${ }^{223}$ y el desarrollo de días de donación de ojos en sus respectivos templos. Estos eventos suelen tener lugar en días de luna llena, como la ceremonia de Vesak/ Vesākha/ Buda Purnima, que conmemora tres eventos clave en la vida del Buda histórico, Shakyamuni: su nacimiento, iluminación (sopadhishesa-nirvana) y fallecimiento de este mundo (mahaparinirvana), momento en que los monjes dan sermones enfatizando la naturaleza meritoria de donar (SIMPSON, 2004, 2017) ${ }^{224}$. En línea con ello, el 18 de diciembre fue designado oficialmente en el

\footnotetext{
${ }^{223}$ Un ejemplo de ello es el monje Kiribathgoda Gnanananda Thero, fundador del monasterio budista Mahamevnawa, en Sri Lanka, que no sólo alienta la donación de órganos tras la muerte sino que él mismo ha donado un órgano, en vida (BBC News, 2016).

${ }^{224}$ Resulta relevante recordar aquí que los budistas atienden a cuatro espacios de autoridad al probar una opinión sobre un problema: a) lo que está escrito en las Escrituras, b) lo que estaría en conformidad con la escritura, c) la tradición del comentario y d) una opinión personal basada en el estudio de los otros tres.
} 
país como Día Nacional de la Donación de Ojos", tomando en cuenta que ese día es el aniversario del nacimiento del Dr. Silva.

La Sociedad de Donación de Ojos del país trabaja independientemente del Banco Nacional de Ojos de Sri Lanka que forma parte del Servicio Nacional de Salud, bajo la autoridad del Ministro de esa área. Dando cuenta de su compromiso con la diversidad, durante años, el cargo de Director Clínico de la organización ha estado a cargo de un islámico. Ello se relaciona con el hecho de que aunque la donación resuena particularmente en creencias budistas, el trabajo de la organización tiende a hacer del acto de donación, un acto social que anima a una comunidad de donantes más extensa y plural. En tal sentido, la dinámica de la organización, su impacto en la comunidad y el desarrollo del banco de ojos, remite al desarrollo humano, entendido como un proceso de ampliación de oportunidades de los individuos, que las personas tienen razón para valorar. Tal ejercicio de la libertad se media por valores (en este caso, de modo particular, el dar, la donación), a su vez influidos por diversas interacciones sociales, en el marco de las potencialidades comunitarias, que se proyectan a su vez a comunidades mayores y diversas.

\section{Conclusiones}

Las dinámicas que las diversas creencias desarrollan en la arena internacional y la visibilidad del factor espiritual en ámbitos relativos al desarrollo, como por ejemplo el del Gross National Happiness Indicator de Bhután, traen a la espiritualidad/religión/creencias a un lugar destacado para considerar, en el contexto dialógico entre las realidades sociales en que se inserta su práctica y ellas, proyectadas hacia el desarrollo humano. Como señala Smith (1996), la religión, al dotar a la vida tal

La tradición Theravada en particular sigue os dos primeros espacios de autoridad más de cerca (Keown, 2001). 
cual es, de un significado y propósito, contribuye a legitimar el mundo como es, al tiempo que como apuntan Brown, Deneulin y Devine (2009) los límites que posee la dimensión "religiosa" de la movilización social son fluidos y el elemento religioso de la movilización social no puede desprenderse de su contexto socio-político.

Las diversas matrices culturales (sus correlatos identitarios y los compromisos comunitarios que convocan) dan lugar a respuestas específicas frente a las mismas necesidades, que pueden plantearse en otros lugares. Ello va a su vez asociado a valores específicos, que orientan la vida de sujetos y comunidades, estableciendo lógicas que guían las interacciones entre sí, con el medioambiente y los otros seres vivos presentes en el planeta. Esas lógicas, asociadas al marco de "tradiciones", implican la construcción de temporalidades específicas, en tanto como bien señala Asad (1986) una tradición se relaciona a un pasado y un futuro a través de un presente, es decir que mientras ese pasado y futuro guardan el poder de transformar tal tradición (espiritual/religiosa/de creencias, en este caso), la materialización de ese poder se concentra en el presente. Resulta de ello necesario entonces, atender a las diversas temporalidades $y$ espacialidades implicadas en las construcciones colectivas en ámbitos de desarrollo (con la perspectiva además, de que las mismas tradiciones -en este caso, religiosas-, en constante movimiento, encuentran modernizaciones/nuevas lecturas y prácticas, que guardan otro potencial para proyectar en el desarrollo, transmitiendo una moral concreta, que deja espacio para la autopoiesis de los practicantes).

En tal sentido, el sangha budista y los valores enfatizados por el budismo en general y el budismo Theravada en particular, constituyen un buen ejemplo para considerar con mayor profundidad el estímulo de valores comunitarios específicos (en este caso religiosos) en el ámbito del desarrollo, atendiendo a su potenciación en construcciones colectivas, que en este caso particular, asocian una temporalidad única entre las vidas pasadas de Buda y su ejemplo, los futuros méritos de la acción de dar, que constituyen la lógica existencial del sujeto que da y su presente de construcción 
colectiva en términos de desarrollo. En ello, el cuerpo aparece como un vector de significación a través del que se construye la evidencia de la relación del sujeto/practicante/actor social con el mundo, propagando significaciones que constituyen la base de su existencia, como individuo y como parte de un colectivo, constituyendo a la acción misma en espacio de enunciación de una perspectiva de desarrollo y transformando las partes corporales donadas en metáforas de dana (LE BRETON, 2002).

El budismo, surgido en India y propagado al mundo, ofrece una ética-psicología, asentada en su idea del no-yo, enfatizando el valor de la intención de la acción y la donación misma, modelando el accionar de los practicantes y potenciando el desarrollo humano en sus comunidades, al mismo tiempo que proyecta tal desarrollo no solamente en el presente sino también en el futuro, porque, por un lado, se espera que las acciones meritorias redunden en buenos frutos en el presente y/o el futuro y por otro lado, esas mismas acciones/donaciones solidarias constituyen una "siembra social" en la comunidad, como ejemplo para los que están y quienes vendrán, repercutiendo no sólo en la región sino fuera de ella.

\section{Referencias}

ALKIRE, S. Religion and Development. In: CLARK, D. A. (Ed.). The Elgar Companion to Development Studies. Cheltenham: Edward Elgar, 2004, p. 502-510.

ALKIRE, S. Dimensions of Human Development. World Development, 30 (2), 2002, 181205.

BBC News. Monk: Donating organs 'good karma'. Recuperado de: https://www.bbc.com/news/av/magazine-35443941/monk-donating-organs-goodkarma. Accedido en 28 de marzo de 2018.

BREKKE, T. Bones of Contention: Buddhist Relics, Nationalism and the Politics of Archaeology. Numen, 54, 2007, p. 270-303. 
BROWN, G; DENEULIN, S.; DEVINE, J. (2009). Contesting the boundaries of religion in social mobilization. Journal of South Asian Development, 10 (1), 2009, p. 22-47.

CANDLAND, Ch. Faith as social capital: religion and community development in Southern Asia. Policy Sciences, 33, 2000, p. 355-374.

COPEMAN, J. The Gift and Its Forms of Life in Contemporary India. Modern Asian Studies 45 (5), 2011, p. 1051-1094.

CHIEW, M. Devotees and well wishers donate blood at Sri Lanka Buddhist Temple in Sentul. The Star (11 de mayo). Recuperado de https://www.thestar.com.my/news/community/2012/05/11/devotees-and-wellwishers-donate-blood-at-sri-lanka-buddhist-temple-in-sentul. Accedido em 13 de noviembre de 2019.

DENEULIN, S.; RAKODI, C. Revisiting Religion: Development Studies Thirty Years On. World Development, Vol. 39, No. 1, 2011 p. 45-54.

DE JONG, J. W. Lo Absoluto en el pensamiento budista. Revista de Estudios Budistas, n. 8, 1994-1995, p. 9-20.

DE LA VALLÉE POUSSIN, L. Karman, retribución de los actos. La doctrina de la retribución del acto. Revista de Estudios Budistas, n. 7, 1930/1994, p. 129-135.

DRAGONETTI, C.; TOLA, F. Dhammapada. La esencia de la sabiduría budista. New Jersey: Primordia, 2004.

DRÈZE J. y Sen, A. India: Economic Development and Social Opportunity. New Delhi: Oxford University Press, 1995.

GAIN, P; JULLIENNE, R; ZHIGUO HE; ALDOSSARY, M; ACQUART, S; COGNASSE, F. \& THURET, G. Global Survey of Corneal Transplantation and Eye Banking. JAMA Ophthalmol. 134(2), 2016, p. 167-173.

GIMÉNEZ, G. La concepción simbólica de la cultura. En Giménez, G. Teoría y análisis de la cultura. México, CONACULTA e Instituto Coahuilense de Cultura, 2005, p. 67-88.

GRIMSON, A. Los límites de la cultura. Crítica de las teorías de la identidad. Buenos Aires: Siglo XXI editors, 2012.

GOULET, D. Development experts: The one-eyed giants. World Development, n. 8 (7-8), 1980, p. 481-489. 
HEIM, M. Theories of the Gift in South Asia: Hindu, Buddhist, and Jain Reflections on Dana. New York: Routledge, 2004/2015.

Hindustan Times. PM Modi arrives in Sri Lanka, prays at country's oldest Buddhist temple. Hindustan Times. Recuperado de https://www.hindustantimes.com/indianews/pm-modi-arrives-in-sri-lanka-prays-at-its-oldest-buddhist-temple/storya6lhWp9Ac7XmG2u6uejFUN.html. Accedido en 14 de septiembre de 2018.

KEOWN, D. Buddhism, Brain Death, and Organ Transplantation. Journal of Buddhist Ethics, Volume 17, 2010, p. 1-34

KLOPPENBORG, R. The role of the Buddhist monk in development activities. Bijdragen tot de Taal-, Land- en Volkenkunde, n. 140 (1), 1984, p. 92-105.

LAMBERT, N.G.; CHAMBERLAIN, W.D. The structure and evolution of eye banking: a review on eye banks' historical, present, and future contribution to corneal transplantation. J Biorepos Sci Appl Med, n. 5, 2017, p. 23-40.

LADWIG, P. Narrative Ethics: the excess of giving and moral ambiguity in the Lao Vessantara - Jataka. In: HEINTZ, M. (Ed.). The Anthropology of Moralities. New YorkOxford: Berghahn Books, 2009, p. 136-160.

LE BRETON, D. La sociología del cuerpo. Buenos Aires: Nueva Visión, 2002.

PERERA, UCP. Review of ethico-legal aspects of tissue retention in the medico-legal practice in Sri Lanka. Galle Medical Journal, n. 11 (1), 2009, p. 32-24.

PNUD. Desarrollo Humano. Informe 1990. Bogotá: Tercer Mundo Editores, 1990.

RATNAYAKA, S. The Bodhisattva Ideal of Theravada. The Journal of the International Association of Buddhist Studies, n. 8 (2), 1985, p. 85-110.

RESTREPO, E. Identidad: apuntes teóricos y metodológicos. En: CASTELLANOS LLANOS, G.; GRUESO, D. I.; RODRIGUEZ, M. (Coords.). Identidad, cultura y política. Perspectivas conceptuales, miradas empíricas. México: Honorable Cámara de Diputados-Universidad del Valle-Miguel Ángel Porrúa, 2010, p. 61-70.

SCHREIBER, J. Politics, Piety, and Biomedicine: The Malaysian Transplant Venture. Germany: Bielefeld, 2017. 
SEWELL, W. H. Jr. The Concept(s) of Culture. En: BONNELL, V. E.; HUNT, L. Beyond the Cultural Turn. Berkeley-Los Angeles-London: University of California Press, 1999, p. 3561.

SILVA, H. The Sri Lanka Experience in Eye Banking. Journal of Refractive Surger, n. 7 (6), 1991, p. 463-465.

SIMPSON, B. Local virtue and global vision. The practice of eye donation in contemporary Sri Lanka. Medicine Anthropology Theory, n. 4 (4), 2017, p. 150-170.

SIMPSON, B. Impossible Gifts: Bodies, Buddhism and Bioethics in Contemporary Sri Lanka. The Journal of the Royal Anthropological Institute, n. 10 (4), 2004, p. $839-859$.

SMITH, C. Correcting a curious neglect, or, bringing religion back in. In: SMITH, C. (Ed.). Disruptive Religion: The Force of Faith in Social Movement Activism. London: Routledge, 1996, p. 1-28.

SUDYKA, L. The gift-of-the-body motif in South Indian narrative tradition and art. The Śibi legend in Andhra. Pandanus '13: Nature in Literature, Art, Myth and Ritual, n. 7(1), 2013, p. 89-106.

THODOCK, C. The Sarvodaya Shramadana Movement in Sri Lanka. Culture Mandala: The Bulletin of the Centre for East West Cultural and Economic Studies, 7 (1), Article 3, 2005.

TOLA, F.; DRAGONETTI, C. Budismo. Unidad y Diversidad. New York: Fundación Instituto de Estudios Budistas, Argentina-The Buddhist Association of the United States, 2004.

TOLA, F.; DRAGONETTI, C. Vidas anteriores de Buda. Jatakas. New Jersey: Primordia Media Inc, 2003.

VADYSINGHE, A.N; DASSANAYAKA, P.B; EDUSSUIRYA, D.H.; RUKSHANA, M.J.F. Tissue donation and transplantation program in Sri Lanka: a medico-legal point of view. Sri Lanka Journal of Forensic Medicine, Science \& Law, n. 9(1), 2018, p. 23-32.

VALCÁRCEL, M. Génesis y Evolución del concepto y enfoques sobre el desarrollo. Documento de investigación. Lima: PUCP, 2006.

VON GLASENAPP, H. Nairatmya (inexistencia del alma) y anishvaratva (inexistencia de Dios). Budismo y religión comparada. Revista de Estudios Budistas, vol. I, n. 2, Octubre 1991 a Marzo 1992, p. 139-147. 
NEARCD: Revista Eletrônica de Antiguidade 2020, Volume XII, Número II - ISSN IS82-8713

Núcleo de Estudas da Antiguidade - NEA

Universidade do Estado do Rio de Janeiro

ISSN 1982-8713

WIJAYANTO, P. A. The supremacy of Dana paramita for the Buddhist laity in daily life. ORIENTASI BARU, n. 18 (1), 2009, p. 51-62.

WIJERATNE, K. By Donating Eyes, Sri Lankans Give Sight to People Worldwide. Global Press Journal (17 de octubre). Recuperado de https://globalpressjournal.com/asia/sri lanka/donating-eyes-sri-lankans-give-sightpeople-worldwide/. Accedido en 17 de octubre de 2016. 